\title{
Pleomorphic adenoma of the breast
}

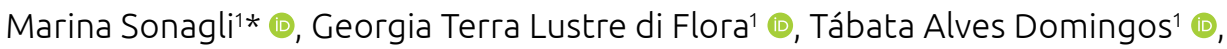 \\ Vinicius Felipe Cardona ${ }^{1} \mathbb{0}$, Solange Maria Torchia de Carvalho' $\mathbb{C}^{\text {, }}$

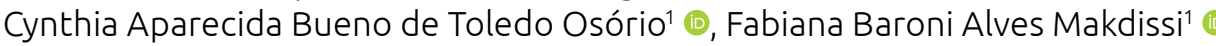

\section{ABSTRACT}

Pleomorphic adenoma (PA) is a common tumor of the salivary gland, but rarely occurs in the breast. PA of the breast is a benign tumor that usually presents as a periareolar nodule. Core-needle biopsies may yield misdiagnosis with complex fibroadenoma, phyllodes tumor and metaplastic breast cancer due to the mixture of stromal and epithelial elements. We present a case of PA of the breast suspected after core-needle biopsy, but confirmed after surgical excision. The importance to make a correct diagnosis consists in avoid extensive unnecessary surgery, such as mastectomy, since PA can be treated with local surgical resection.

KEYWORDS: adenoma, pleomorphic; breast neoplasms; neoplasms, glandular and epithelial.

\section{INTRODUCTION}

Pleomorphic adenoma (PA) is a benign tumor commonly found in the parotid gland, but rarely described in breasts ${ }^{1}$. PA is a mixed tumor, composed of epithelial and myoepithelial elements, which can occur in either breast or parotid tissues due to its common embryological ectodermal origin ${ }^{2}$. Accurate identification is important to avoid misdiagnosis such as a primary sarcoma, an adenomyoepithelioma, a Phyllodes tumor or metaplastic breast carcinoma that may lead to unnecessary extensive surgery $y^{3-5}$. Thus, we report a case of a PA suspected after core needle biopsy and confirmed after surgical excision.

\section{CASE REPORT}

An asymptomatic 71-year-old woman presented a lump in her right breast during breast cancer screening. Mammography and breast ultrasound showed a periareolar, irregular and hypoechoic lump in the lower internal quadrant of the right breast, measuring $9 \mathrm{~mm}$ (Figure 1). Core-needle biopsy demonstrated a benign biphasic neoplasm, composed of a mixture of epithelial and myoepithelial cells, with a focus of apocrine metaplasia, sclerosing adenosis, and chondromyxoid stroma (Figure 2). Immunohistochemistry revealed p63 and calponin expression in myoepithelial cells, in addition to a low Ki67 proliferation index (Figure 2). Based on histopathological findings, it was not possible to differentiate between complex fibroadenoma and PA of the breast. Consequently, the patient underwent surgical excision of the nodule. Examination of the surgical specimen showed a well-defined lesion with clear margins, and characteristic epithelial and myoepithelial elements without atypia, embedded into a chondromyxoid stroma, with foci of chondroid metaplasia (Figure 3). Final pathological report confirmed PA of the breast.

This study was approved by the Ethics and Research Committee of the A.C. Camargo Cancer Center (number 4.213.207) and was conducted following the Helsinki Declaration principles. All information and images were de-identified.

\section{DISCUSSION}

PA of the breast was first reported in $1906^{6}$. Since then, less than a hundred cases have been reported worldwide, including one from Brazi ${ }^{37-12}$. PA typically occurs in females between 23 to 85 years of age ${ }^{7}$ and is usually located in the periareolar region and in the right breast ${ }^{13}$. PA presents clinically as a breast nodule with an average size of $2 \mathrm{~cm}$, which can be palpable and difficult to differentiate from breast cancer ${ }^{1,1,14}$.

There are no specific imaging findings of $\mathrm{PA}^{11}$. Although PA is often reported as a well-circumscribed lump, it may demonstrate irregular contours on breast ultrasound and can appear as a lump without microcalcifications on mammography ${ }^{3}$. On pathological examination, PA appears as a circumscribed lesion that is clearly demarcated from the surrounding tissue, and is characterized by a mixture of epithelial and mesenchymal components such as glandular ducts, myoepithelial cells, myxomatous stroma, and cartilaginous

${ }^{1}$ A.C. Camargo Cancer Center - São Paulo (SP), Brazil.

*Corresponding author: marina.sonagli@accamargo.org.br

Conflict of interests: nothing to declare.

Received on: 10/05/2020. Accepted on: 11/26/2020 


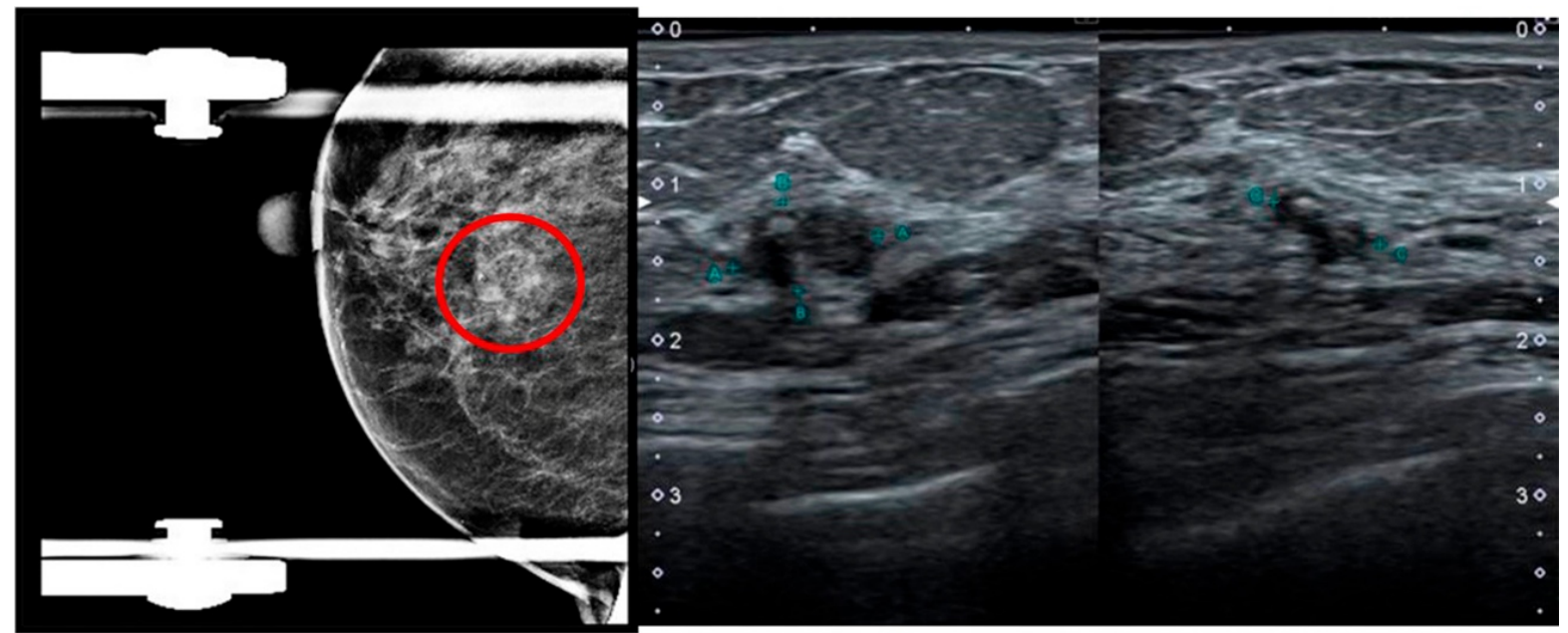

Figure 1. Mammography (left) and ultrasound (right) demonstrating a 9 mm hypoechoic and irregular nodule in the lower internal quadrant of the right breast.

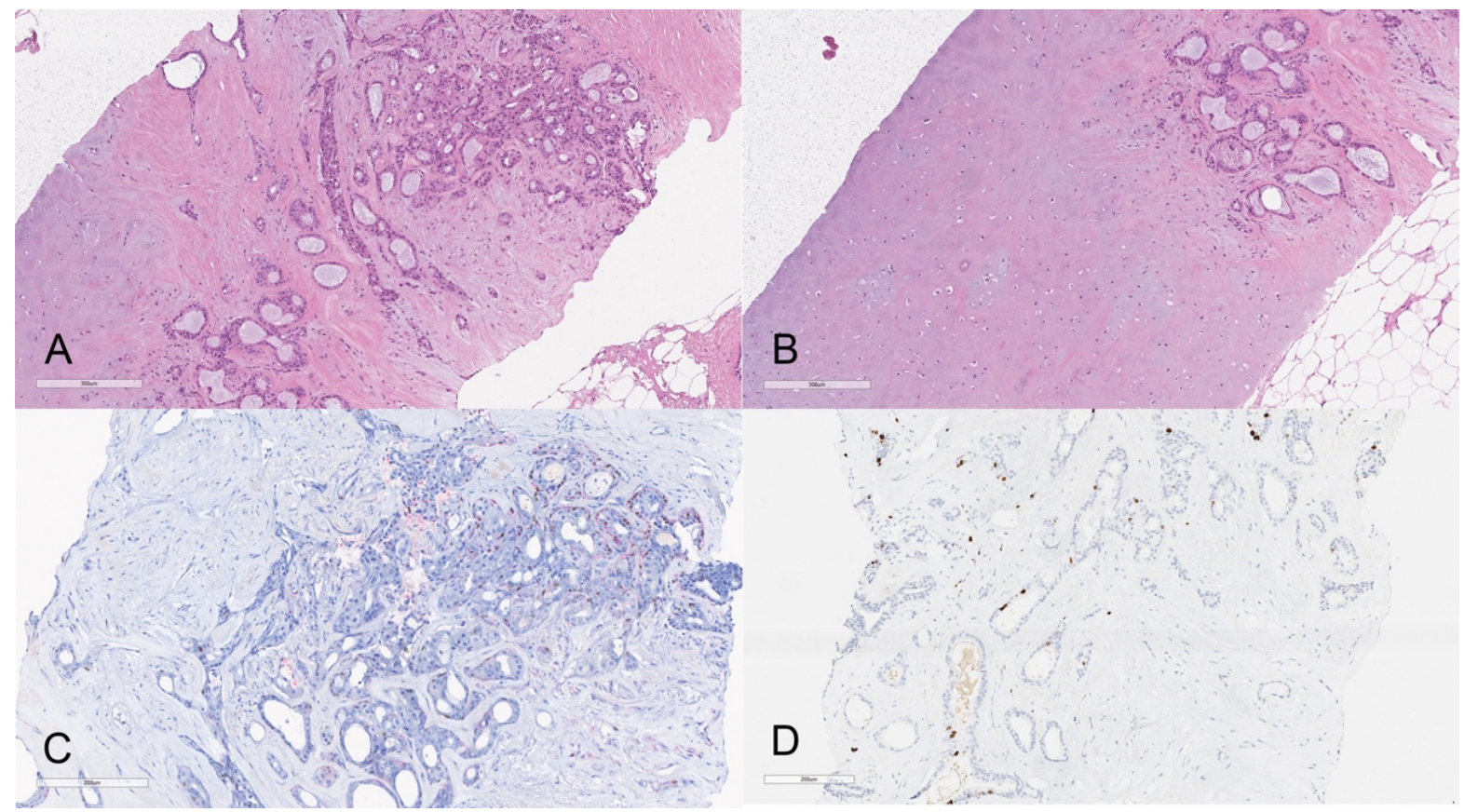

Figure 2. Hematoxylin-eosin stain (100x) of core-needle biopsy specimen of (A) the right breast lump showing glands surrounded by epithelial and myoepithelial cells and (B) focus of chondromyxoid stroma. Immunohistochemical (100x) of core-needle biopsy specimen of the right breast lump showing positivity for p63 (nuclear) and (C) calponin (cytoplasmatic) expression in myoepithelial cells and (D) low Ki67 proliferation rate.

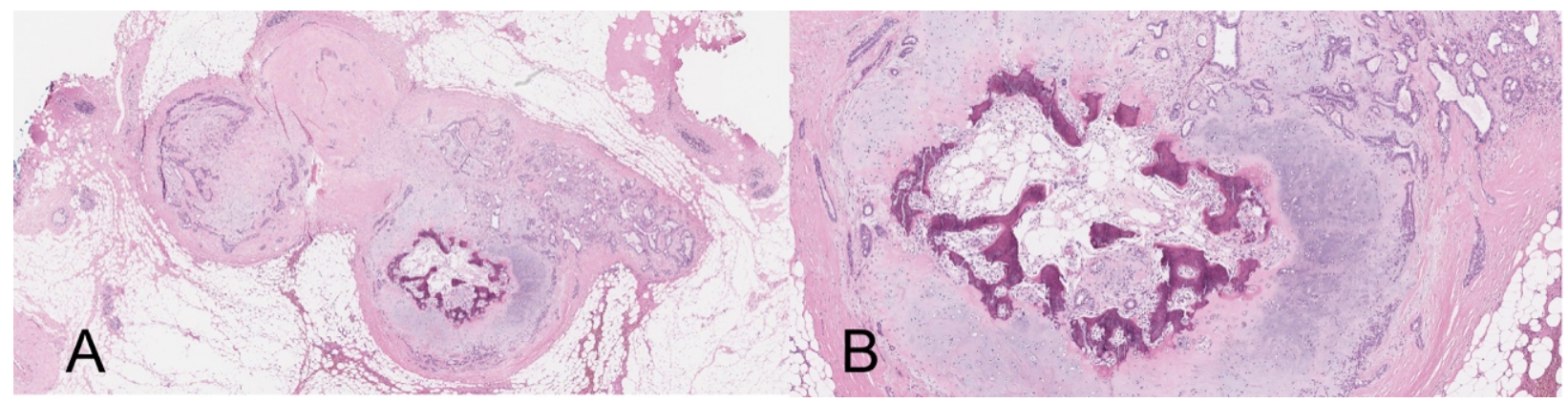

Figure 3. (A) Hematoxylin-eosin stain of surgical specimen showing a well-defined lesion under low-power magnification (40x) and (B) a high-power magnification (200x) of pleomorphic adenoma with glandular elements in chondromyxoid stroma with cartilaginous and osseous metaplasia. 
components. PA diagnosis can be difficult in core biopsy specimens because it must be differentiated from complex fibroadenoma or phyllodes tumor ${ }^{1,3,4,15}$. In addition, two case reports have described misdiagnoses of breast PA identified as matrix-producing metaplastic breast cancer in core-needle biopsy specimens ${ }^{4,15}$.

Recommended treatment is local resection with $3 \mathrm{~mm}$ of clear margins to avoid disruption of the tumor capsule ${ }^{2,4}$.PA is an indolent tumor, but recurrences have been reported ${ }^{2,13}$. Recurrence is usually in the adjacent subareolar area, with an average postoperative recurrence interval of 4 years ${ }^{2,4}$.

\section{CONCLUSIONS}

BreastPA is a rare tumor that presents clinically as a periareolar nodule. Despite its being a benign tumor, the diagnosis from core-needle biopsy specimens is difficult due to the mixture of stromal and epithelial elements that can raise a differential diagnosis of complex fibroadenoma, phyllodes tumor, and metaplastic breast cancer. This case illustrates a presentation of a breast lump in an elderly patient for whom breast cancer was the primary diagnostic consideration. Diagnostic accuracy is essential to avoid extensive surgical overtreatment such as mastectomy, as PA can be cured by local surgical resection.

\section{ACKNOWLEDGMENTS}

We thank the A.C. Camargo Cancer Center research department for all the support during the writing of this case report.

\section{AUTHORS' CONTRIBUTIONS}

M.S.: Conceptualization, Project administration, Writing — original draft, Writing — review \& editing.

G.T.L.F.: Writing - original draft.

T.A.D.: Writing — original draft, Writing — review \& editing.

V.F.C.: Writing - original draft, Writing — review \& editing.

S.M.T.C.: Writing - review \& editing.

C.A.B.T.O.: Writing — review \& editing,

F.B.A.M.: Supervision, Writing — review \& editing.

\section{REFERENCES}

1. Reid-Nicholson M,Bleiweiss I,PaceB,Azueta V,Jaffer S.Pleomorphic adenoma of the breast:A case report and distinction from mucinous carcinoma. Arch Pathol Lab Med. 2003;127(4):474-7. https://doi. org/10.1043/0003-9985(2003)127\%3C0474:paotb\%3E2.0.co;2

2. John BJ, Griffiths C, Ebbs SR. Pleomorphic adenoma of the breast should be excised with a cuff of normal tissue. Breast J. 2007;13(4):418-20. https://doi.org/10.1111/j.1524-4741.2007.00452.x

3. Takahashi K. Diagnosis of an extremely rare pleomorphic adenoma of the breast with core needle biopsy: A case report. Ann Med Surg. 2018;36:242-5. https://doi.org/10.1016/j.amsu.2018.10.037

4. Djakovic A, Engel JB, Geisinger E, Honig A, Tschammler A, Dietl J. Pleomorphic adenoma of the breast initially misdiagnosed as metaplastic carcinoma in preoperative stereotactic biopsy: a case report and review of the literature. Eur J Gynaecol Oncol. 2011;32(4):427-30.

5. Foschini MP, Krausz T. WHO Classification of Tumours. Breast Tumours. In: WHO Classification of Tumours Editorial Board, editor. WHO Classification of tumour series. $5^{\text {th }}$ ed. Lyon: International Agency for Research on Cancer; 2019. p. 40-2.

6. Lecène AL. Observation d'un cas de tumeur "mixte" du sein. Rev Chir. 1906;33:434-68.

7. Khamechian T, Alizargar J, Mazoochi T. Reporting a Rare Case of Pleomorphic Adenoma of the Breast. Case Rep Med. 2014;2014:387183. https://doi.org/10.1155/2014/387183

8. Di Bonito M, Cantile M, Cerrone M, Liguori G, Botti G. Synchronous Pleomorphic Adenoma and Invasive Ductal Carcinoma in Distinct Breasts. Breast J. 2015;21(4):428-30. https://doi.org/10.1111/tbj.12426
9. Srinivasamurthy BC, Bhat RV, Gopal SV. A rare benign tumor of breast masquerading on fine needle aspiration cytology: A case report. Breast Dis. 2017;37(2):105-7. https://doi. org/10.3233/bd-170270

10. Nestarez JE, Corrêa MAC, Simöes AB, Cominotti MLM, Barreto E, Rosa JAV. Adenoma pleomórfico da mama. Rev Bras Mastol. 1998;8(3):164-6.

11. Leekha N, Muralee M, Mathews A, Preethi TR, Ahamed MI. Pleomorphic Adenoma of Breast-A Case Report and Review of Literature. Indian J Surg Oncol. 2014;5(2):152-4. https://doi. org/10.1007/s13193-014-0310-y

12. Arslan A, Güldoğan N, Kapucuoğlu N, Esen G, Kara H, Uras C. A rare case of pleomorphic adenoma of the breast: Ultrasonography and pathology findings. Breast J. 2018;24(6):1069-70. https://doi.org/10.1111/tbj.13133

13. Diaz NM, McDivitt RW, Wick MR. Pleomorphic adenoma of the breast: A clinicopathologic and immunohistochemical study of 10 cases. Hum Pathol. 1991;22(12):1206-14. https://doi. org/10.1016/0046-8177(91)90102-u

14. Sato K, Ueda Y, Shimasaki M, Ozaki M, Nitta N, Chada K, et al. Pleomorphic adenoma (benign mixed tumor) of the breast: A case report and review of the literature. Pathol Res Pract. 2005;201(4):333-9. https://doi.org/10.1016/j. prp.2005.03.004

15. Rakha EA, Aleskandarany MA, Samaka RM, Hodi Z, Lee AHS, Ellis IO. Pleomorphic adenoma-like tumour of the breast. Histopathology. 2016;68(3):405-10. https://doi.org/10.1111/ his. 12757

(c) 2021 Brazilian Society of Mastology

This is an open access article distributed under the terms of the Creative Commons license. 